\title{
Association between GDF5 rs143383 genetic polymorphism and musculoskeletal degenerative diseases susceptibility: a meta-analysis
}

\author{
Xin Huang ${ }^{1}$, Weiyue Zhang ${ }^{2}$ and Zengwu Shao ${ }^{1 *}$ (1)
}

\begin{abstract}
Background: Several studies have assessed the association between GDF5 rs143383 polymorphism and the susceptibility of musculoskeletal degenerative diseases, such as intervertebral disc degeneration (IDD) and osteoarthritis (OA), but the results are inconsistent. The aim of our study was to evaluate the association between them comprehensively.

Methods: A systematical search was conducted on PubMed, Scopus, Web of Science (WOS), Embase, and the Cochrane Library databases updated to April 20, 2018. Eligible studies about polymorphisms in GDF5 gene and risk of IDD or OA were included. Pooled odds ratios (ORs) and 95\% confidence intervals (95\% Cls) were utilized.

Results: Fifteen studies with a total of 5915 cases and 12,252 controls were finally included in our study. Meta-analysis of GDF5 rs143383 polymorphism was statistically associated with increased risk of musculoskeletal degenerative diseases under each genetic model (allele model: $O R=1.32,95 \% \mathrm{Cl} 1.19-1.48, P=0.000$; homozygote model: $\mathrm{OR}=1.80,95 \% \mathrm{Cl} 1.49-2.16, P=0.000$; heterozygote model: $\mathrm{OR}=1.37,95 \% \mathrm{Cl} 1.21-1.55, \mathrm{P}=0.000$; dominant model: $\mathrm{OR}=1.56,95 \% \mathrm{Cl} 1.39-1.75, P=0.000$; recessive model: $\mathrm{OR}=1.39,95 \% \mathrm{Cl} 1.20-1.60, P=0.000)$. Stratified analyses based on disease type showed a significant association between the GDF5 rs143383 polymorphism and increased risk of IDD and OA under all genetic models studied. When stratified with ethnicity, pooled outcomes revealed that this polymorphism was significantly related with increased risk of musculoskeletal degenerative diseases in both Asian and Caucasian populations under all genetic models studied.
\end{abstract}

Conclusions: The present study suggested that GDF5 rs143383 polymorphism was significantly associated with susceptibility to musculoskeletal degenerative diseases.

Keywords: GDF5 gene, Polymorphisms, Musculoskeletal degenerative diseases, Meta-analysis

\section{Background}

Intervertebral disc degeneration (IDD) and osteoarthritis (OA) are two major musculoskeletal degenerative diseases that bring about pain, physical limitations and disability of patients. IDD has been one of the important causes to low back pain (LBP) and motor deficiency. Lumbar disc herniation (LDH) is caused mainly by IDD because the degeneration and herniation of nucleus pulposus exist in the lumbar intervertebral disc [1]. OA is a

\footnotetext{
* Correspondence: szwproa@163.com

1 Department of Orthopaedics, Union Hospital, Tongji Medical College, Huazhong University of Science and Technology, Wuhan 430022, China Full list of author information is available at the end of the article
}

chronic age-associated disease resulted from articular cartilage degeneration $[2,3]$, which has a profound influence on the functioning of synovial joints, primarily the knee, hip, and hands [3]. Apart from aging, hormonal, environmental and behavioral factors, genetic factor has been implicated in the etiology and pathogenesis of musculoskeletal degenerative diseases [4-6].

Growth differentiation factor 5 (GDF5) is a member of the transforming growth factor- $\beta$ (TGF- $\beta$ ) superfamily with high articular cartilage specificity [7]. Studies have revealed the significant value of GDF5 gene in musculoskeletal processes including endochondral ossification, synovial joint formation, tendon repair and bone production [8-10]. It is

(c) The Author(s). 2018 Open Access This article is distributed under the terms of the Creative Commons Attribution 4.0 International License (http://creativecommons.org/licenses/by/4.0/), which permits unrestricted use, distribution, and reproduction in any medium, provided you give appropriate credit to the original author(s) and the source, provide a link to the Creative Commons license, and indicate if changes were made. The Creative Commons Public Domain Dedication waiver (http://creativecommons.org/publicdomain/zero/1.0/) applies to the data made available in this article, unless otherwise stated. 
also suggested that GDF5 is effective in enhancing the proliferation and matrix anabolism of intervertebral disc cells [11-13]. The $+104 \mathrm{~T} / \mathrm{C}$ polymorphism (rs143383) in the 5 '-untranslated region (UTR) of GDF5 gene influences transcriptional activity in the gene core promoter, and lower GDF5 expression has been detected in individuals carrying $\mathrm{T}$ alleles.

Although several meta-analyses have revealed a possible relationship between the GDF5 rs143383 and knee OA and other common phenotypes OA [6, 14-16], several new studies have also reported an association between rs143383 and the risk of IDD [17-19] and other phenotypes of OA [5, 20-23]. Therefore, the data needs to be updated and more reliable studies are warranted to conclude whether the association varies by disease type and ethnicity. Our study conducted a meta-analysis to shed some light on the relationship between GDF5 rs143383 polymorphism and the susceptibility of IDD and OA using all published case-control association studies.

\section{Methods}

\section{Search strategy}

A computerized literature search was conducted in the PubMed, Scopus, Web of Science (WOS), Embase, and the Cochrane Library databases up to April 20, 2018. The search method of our study followed the terms such as: (IDD" or "LDD" or "LDH" or "LBP" or "Intervertebral Disc Degeneration" or "OA" or "osteoarthritis") and ("GDF5" or "rs143383" or "GDF5 + $104 \mathrm{~T} / \mathrm{C}$ ") and ("polymorphisms" or "variants" or "variation" or "SNP"). Eligible articles that matched the inclusion criteria were included. Moreover, the references of articles were examined one by one to avoid missing any eligible studies. When the important data were not available, we tried to contact researchers of some articles.

\section{Inclusion and exclusion criteria}

A study that is eligible for inclusion must meet the following criteria: (1) case-control study or cohort study including both case and control groups, (2) detection of GDF5 polymorphisms and IDD or OA risk, (3) having an accessible genotype frequency for calculating an odds ratio (OR) or hazard ratio (HR) with 95\% confidence interval (95\% CI), (4) genotype frequencies in controls must conform to Hardy-Weinberg equilibrium (HWE). Whereas, reviews, case reports or serious, or similar works were all eliminated. We also eliminated the studies with genotype frequencies not in HWE [24].

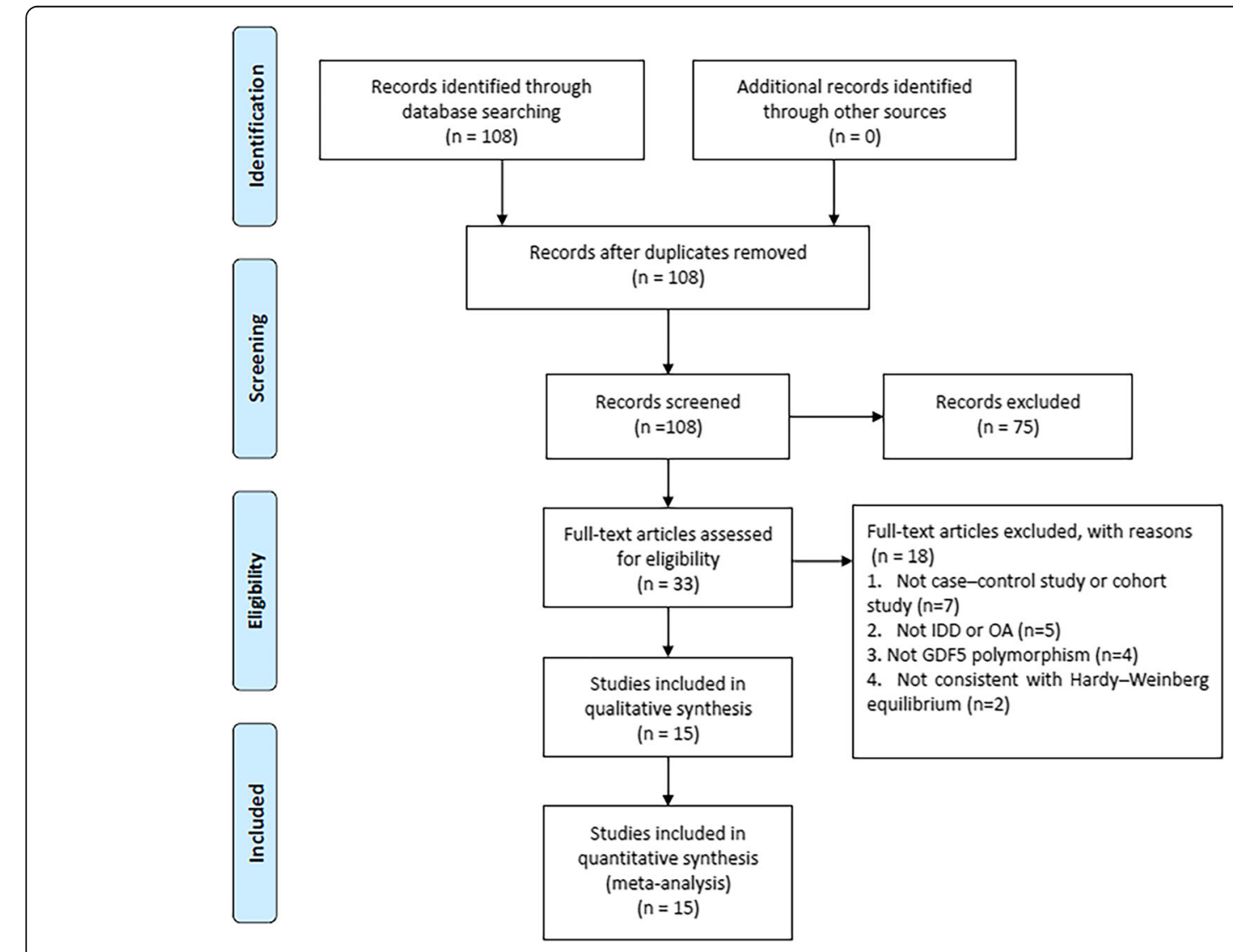

Fig. 1 Flowchart of the study selection process 


\section{Data extraction and quality assessment}

Two investigators (Xin Huang, Weiyue Zhang) were assigned to assess the eligibility of all studies. And the relevant data for analysis were extracted on their own. Moreover, a third investigator (Zengwu Shao) resolved the disagreements when necessary. The important data were collected as follows: name of first author, year, countries, ethnicity, sample size, disease, sex, age, genotyping methods, and allele frequencies of GDF5 rs143383. The study quality was assessed in accordance with the Newcastle-Ottawa Scale (NOS). The study was considered high quality with the scores were $\geq 7$.

\section{Statistical analysis}

The statistical data was analyzed by Stata version 14.0. Outcomes were calculated by odds ratios (ORs) and 95\% confidence intervals (CIs). Genotype frequencies of GDF5 rs143383 polymorphism for HWE were calculated using the chi-square test, and $P<0.05$ was regarded as significant disequilibrium. The chi-square test and the $\mathrm{I}^{2}$ statistic were utilized to assess the between-study heterogeneity. If an $\mathrm{I}^{2}$ value of $<50 \%$, it was considered that no significant heterogeneity existed [25]. A random effects model was utilized when there was a significant heterogeneity. On the contrary, the fixed effects model was utilized. Moreover, we further made subgroup analyses to evaluate the source of heterogeneity. Begg's and Egger's methods were mainly utilized to assess publication bias. And sensitivity analyses were to evaluate the stability of major outcomes and possible source of heterogeneity.

\section{Results}

Search results

The study search is shown in the flow diagram (Fig. 1). 108 relevant articles were collected during the databases search. Furthermore, 75 were eliminated during

Table 1 Main characteristics of the studies included in this meta-analysis

\begin{tabular}{|c|c|c|c|c|c|c|c|c|c|c|c|}
\hline \multirow[t]{2}{*}{ First author } & \multirow[t]{2}{*}{ Year } & \multirow[t]{2}{*}{ Country } & \multirow[t]{2}{*}{ Ethnicity } & \multicolumn{2}{|c|}{ Sample size } & \multirow[t]{2}{*}{ Disease } & \multirow[t]{2}{*}{ Sex } & \multirow{2}{*}{$\begin{array}{l}\text { Age } \\
(y)\end{array}$} & \multirow[t]{2}{*}{ Genotyping method } & \multirow[t]{2}{*}{ Quality } & \multirow[t]{2}{*}{ Citation } \\
\hline & & & & Case & Control & & & & & & \\
\hline$\overline{M u J}$ & 2014 & China & Asian & 231 & 370 & $\mathrm{LDH}$ & Both & 21.9 & DNA analyzers & $Y$ & {$[17]$} \\
\hline Mu J & 2013 & China & Asian & 305 & 587 & LBP & Both & 48.4 & DNA analyzers & Y & {$[18]$} \\
\hline Williams FMK a & 2011 & UK & Caucasian & 194 & 1268 & LDD & Both & 65.7 & KASPar chemistry & Y & {$[19]$} \\
\hline Williams FMK ${ }^{b}$ & 2011 & UK & Caucasian & 33 & 539 & LDD & Both & 54.7 & KASPar chemistry & Y & {$[19]$} \\
\hline Williams FMK ${ }^{c}$ & 2011 & UK & Caucasian & 54 & 704 & LDD & Both & 62.9 & KASPar chemistry & Y & {$[19]$} \\
\hline Williams FMK ${ }^{d}$ & 2011 & UK & Caucasian & 18 & 574 & LDD & Both & 53.6 & KASPar chemistry & Y & {$[19]$} \\
\hline Williams FMK ${ }^{e}$ & 2011 & UK & Caucasian & 14 & 116 & LDD & Both & 65.8 & KASPar chemistry & Y & {$[19]$} \\
\hline Tülüce Y & 2017 & Turkey & Caucasian & 95 & 77 & $\mathrm{OA}$ & Both & 62.5 & PCR-RFLP & Y & {$[20]$} \\
\hline $\begin{array}{l}\text { Abd Elazeem } \\
\text { Ml }\end{array}$ & 2017 & Egypt & Caucasian & 50 & 50 & Primary knee OA & Both & 56.5 & TaqMan & Y & {$[21]$} \\
\hline Sabah-Ozcan S & 2016 & Turkey & Caucasian & 94 & 279 & Knee OA & Both & 58.4 & PCR-RFLP & Y & {$[22]$} \\
\hline Xiao JL & 2015 & China & Asian & 114 & 126 & $\begin{array}{l}\text { Temporomandibular joint } \\
\text { OA }\end{array}$ & Both & 33.6 & PCR-RFLP & Y & {$[23]$} \\
\hline Mishra A & 2013 & India & Asian & 300 & 300 & Knee OA & Both & 54.0 & PCR-RFLP & Y & {$[5]$} \\
\hline $\begin{array}{l}\text { Tawonsawatruk } \\
\mathrm{T}\end{array}$ & 2011 & Thailand & Asian & 90 & 103 & Knee OA & Both & 68.5 & PCR-RFLP & Y & {$[29]$} \\
\hline Cao Z & 2010 & Korea & Asian & 276 & 298 & Knee OA & Both & 63.0 & PCR-RFLP & Y & {$[30]$} \\
\hline Valdes AM & 2009 & UK & Caucasian & 259 & 509 & Knee OA & Both & 68.5 & Allele-specific PCR & Y & {$[31]$} \\
\hline Tsezou A & 2007 & Greece & Caucasian & 251 & 268 & Knee OA & Both & 67.9 & Direct sequence & Y & {$[32]$} \\
\hline Miyamoto $Y^{a}$ & 2007 & Japan & Asian & 718 & 861 & Knee OA & Both & 71.9 & TaqMan & Y & {$[33]$} \\
\hline Miyamoto $Y^{b}$ & 2007 & China & Asian & 313 & 485 & Knee OA & Both & 58.8 & TaqMan & Y & {$[33]$} \\
\hline Miyamoto $Y^{c}$ & 2007 & Japan & Asian & 998 & 983 & Hip OA & Both & 71.9 & TaqMan & Y & {$[33]$} \\
\hline Southam L ${ }^{a}$ & 2007 & UK & Caucasian & 509 & 822 & Knee OA & Both & 65.0 & PCR-RFLP & Y & {$[34]$} \\
\hline Southam $L^{b}$ & 2007 & Spain & Caucasian & 274 & 1196 & Knee OA & Both & 65.0 & TaqMan & Y & [34] \\
\hline Shin $M H$ & 2012 & Korea & Asian & 725 & 1737 & Knee OA & Both & 67.4 & $\begin{array}{l}\text { High resolution melting } \\
\text { analysis }\end{array}$ & Y & {$[35]$} \\
\hline
\end{tabular}

$\overline{a, b, c, d} a{ }^{e}$ denote an independent study in one article, respectively; $L D D$ lumbar disc degeneration, $L D H$ lumbar disc herniation, $L B P$ low-back pain, $O A$ osteoarthritis, $R T$-PCR real-time polymerase chain reaction, $P C R$ - $R F L P$ polymerase chain reaction-restriction fragment-length polymorphism, $Y$ yes 
abstract review, and 33 for further review. During the full-text review, 18 articles were eliminated for the following reasons: seven were neither case-control study or cohort study, five were not associated with IDD or OA, four were not GDF5 polymorphisms on IDD or OA risk, two was not consistent with HWE. To sum up, 15 studies with 5915 cases and 12,252 controls were included in the present study.

\section{Study selection and characteristics}

The main features of each eligible study are summarized in details (Table 1). Among these eligible studies, three articles investigated value of GDF5 rs143383 in IDD risk in seven independent populations. In addition, twelve articles examined effects of GDF5 rs143383 on the risk of OA in fifteen independent populations. Ten in the included studies had been made among Asian populations, and twelve were in Caucasian populations. The years for publication ranged from 2007 to 2017. In all these articles, genotype frequencies in controls conformed to HWE (Table 2). According to NOS, the quality scores of all eligible articles ranged from 7 to 8 , which indicated a good quality (Additional file 1: Table S1). Furthermore, the definitions of diseases, inclusions, and exclusions of patients in each study are also shown (Additional file 1: Table S2).

\section{Association between GDF5 rs 143383 and musculoskeletal degenerative diseases}

A total of 5915 patients and 12,252 controls were included in our study on GDF5 rs143383 polymorphism. There was a significant relationship between GDF5 rs143383 polymorphism and increased risk of musculoskeletal degenerative diseases under each genetic model (allele model: $\mathrm{OR}=1.32,95 \%$ CI $1.19-1.48, P=0.000$; homozygote model: $\mathrm{OR}=1.80,95 \% \mathrm{CI} 1.49-2.16, P=$ 0.000 ; heterozygote model: $\mathrm{OR}=1.37,95 \% \mathrm{CI} 1.21-1.55$, $P=0.000$; dominant model: $\mathrm{OR}=1.56,95 \% \mathrm{CI} 1.39-1.75$, $P=0.000$; recessive model: $\mathrm{OR}=1.39,95 \%$ CI $1.20-1.60$, $P=0.000$ ) (Fig. 2 and Table 3). The heterogeneity of studies on this polymorphism was $<50 \%$, under homozygote, heterozygote and dominant models.

Table 2 Genotype distribution of the studies included in this meta-analysis

\begin{tabular}{|c|c|c|c|c|c|c|c|c|c|c|}
\hline \multirow{2}{*}{$\begin{array}{l}\text { Study ID } \\
\text { GDF5 rs143383 }\end{array}$} & \multirow[t]{2}{*}{ Year } & \multirow[t]{2}{*}{ Ethnicity } & \multirow[t]{2}{*}{ Disease } & \multicolumn{3}{|c|}{ Case group } & \multicolumn{3}{|c|}{ Control group } & \multirow[t]{2}{*}{$P$ for HWE } \\
\hline & & & & $\mathrm{CC}$ & $\mathrm{CT}$ & $\pi$ & $\mathrm{CC}$ & $C T$ & $\Pi$ & \\
\hline $\mathrm{MuJ}$ & 2014 & Asian & $\mathrm{LDH}$ & 8 & 79 & 144 & 39 & 158 & 173 & 0.743 \\
\hline Mu J & 2013 & Asian & LBP & 10 & 89 & 206 & 58 & 254 & 275 & 0.953 \\
\hline Williams FMK a & 2011 & Caucasian & LDD & 21 & 103 & 70 & 218 & 586 & 464 & 0.159 \\
\hline Williams FMK b & 2011 & Caucasian & LDD & 4 & 14 & 15 & 94 & 252 & 193 & 0.453 \\
\hline Williams FMK ${ }^{c}$ & 2011 & Caucasian & LDD & 6 & 23 & 25 & 119 & 312 & 273 & 0.067 \\
\hline Williams FMK ${ }^{d}$ & 2011 & Caucasian & LDD & 2 & 7 & 9 & 72 & 256 & 246 & 0.671 \\
\hline Williams FMK ${ }^{e}$ & 2011 & Caucasian & LDD & 1 & 8 & 5 & 16 & 42 & 58 & 0.073 \\
\hline Tülüce $Y$ & 2017 & Caucasian & $\mathrm{OA}$ & 24 & 39 & 32 & 8 & 39 & 30 & 0.366 \\
\hline Abd Elazeem Ml & 2017 & Caucasian & $\mathrm{OA}$ & 14 & 16 & 20 & 13 & 25 & 12 & 0.998 \\
\hline Sabah-Ozcan S & 2016 & Caucasian & $\mathrm{OA}$ & 14 & 43 & 37 & 52 & 153 & 74 & 0.083 \\
\hline Xiao J & 2015 & Asian & $\mathrm{OA}$ & 5 & 47 & 62 & 19 & 54 & 53 & 0.396 \\
\hline Mishra & 2013 & Asian & $\mathrm{OA}$ & 46 & 130 & 124 & 56 & 160 & 84 & 0.188 \\
\hline Tawonsawatruk T & 2011 & Asian & $\mathrm{OA}$ & 11 & 41 & 38 & 23 & 47 & 33 & 0.424 \\
\hline Cao Z & 2010 & Asian & $\mathrm{OA}$ & 11 & 115 & 150 & 26 & 113 & 159 & 0.397 \\
\hline Valdes AM & 2009 & Caucasian & $\mathrm{OA}$ & 35 & 98 & 126 & 84 & 244 & 181 & 0.908 \\
\hline Tsezou A & 2007 & Caucasian & $\mathrm{OA}$ & 30 & 126 & 95 & 44 & 125 & 99 & 0.669 \\
\hline Miyamoto $Y^{a}$ & 2007 & Asian & $\mathrm{OA}$ & 31 & 243 & 444 & 58 & 330 & 473 & 0.966 \\
\hline Miyamoto $Y^{b}$ & 2007 & Asian & $\mathrm{OA}$ & 19 & 97 & 197 & 48 & 193 & 244 & 0.283 \\
\hline Miyamoto $Y^{c}$ & 2007 & Asian & $\mathrm{OA}$ & 31 & 266 & 701 & 70 & 371 & 542 & 0.552 \\
\hline Southam $L^{a}$ & 2007 & Caucasian & $\mathrm{OA}$ & 52 & 238 & 219 & 126 & 372 & 324 & 0.262 \\
\hline Southam $L^{b}$ & 2007 & Caucasian & $\mathrm{OA}$ & 36 & 136 & 102 & 194 & 563 & 439 & 0.549 \\
\hline Shin $\mathrm{MH}$ & 2012 & Asian & $\mathrm{OA}$ & 38 & 305 & 382 & 106 & 689 & 942 & 0.176 \\
\hline
\end{tabular}

$\mathrm{a}, \mathrm{b}, \mathrm{c}, \mathrm{d}$ and ${ }^{\mathrm{e}}$ denote an independent study in one article, respectively, HWE Hardy-Weinberg equilibrium, $L D D$ lumbar disc degeneration, $L D H$ lumbar disc herniation, $L B P$ low-back pain, $O A$ osteoarthritis 

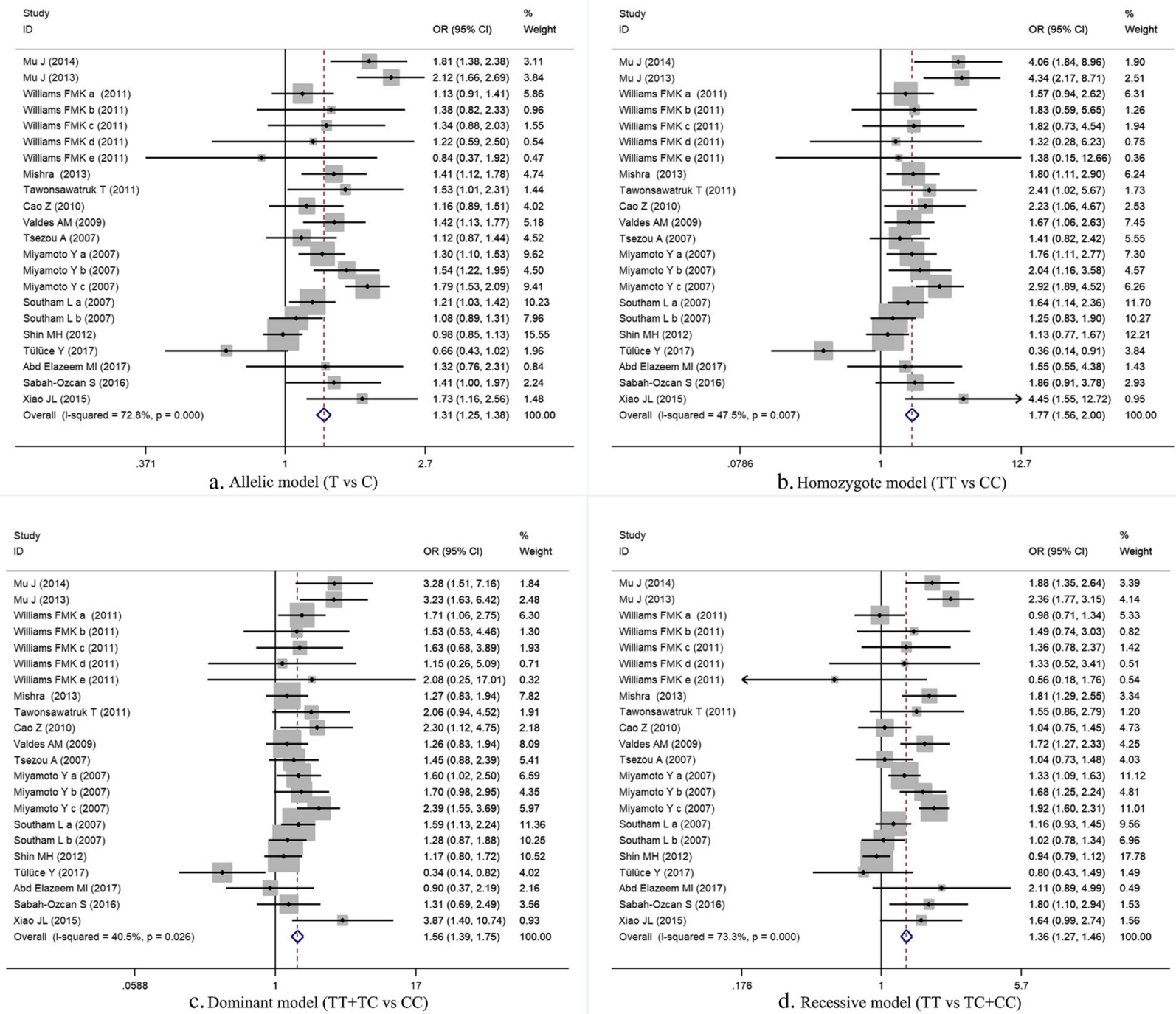

Fig. 2 (a) Meta-analysis for GDF5 rs143383 polymorphism under allele model; (b) Meta-analysis for GDF5 rs143383 polymorphism under homozygote model; (c) Meta-analysis for GDF5 rs143383 polymorphism under dominant model; (d) Meta-analysis for GDF5 rs143383 polymorphism under recessive model

\section{Subgroup analysis}

Because of heterogeneity, we conducted stratified analyses based on different disease types and ethnicity. Stratified analyses based on disease type revealed a significant relationship between the GDF5 rs143383 polymorphism and increased risk of IDD under all genetic models studied (allele model: OR $=1.45$, 95\% CI $1.13-$ 1.86, $P=0.004$; homozygote model: $\mathrm{OR}=2.33,95 \% \mathrm{CI}$ $1.55-3.51, P=0.000$; heterozygote model: $\mathrm{OR}=1.84$, 95\%CI 1.34-2.52, $P=0.000$; dominant model: $\mathrm{OR}=2.11$, 95\%CI 1.57-2.86, $P=0.000$; recessive model: $\mathrm{OR}=1.44$, 95\%CI 1.02-2.04, $P=0.037$ ). Additionally, rs 143383 polymorphism was related with increased OA risk in all genetic models (allele model: $\mathrm{OR}=1.28,95 \% \mathrm{CI} 1.28$ 1.14-1.44, $\mathrm{P}=0.000$; homozygote model: $\mathrm{OR}=1.67,95 \% \mathrm{CI}$
1.36-2.05, $P=0.000$; heterozygote model: $\mathrm{OR}=1.29,95 \% \mathrm{CI}$ $1.13-1.48, P=0.000$; dominant model: $\mathrm{OR}=1.46,95 \% \mathrm{CI}$ $1.29-1.66, P=0.000$; recessive model: $\mathrm{OR}=1.35,95 \% \mathrm{CI}$ $1.16-1.59, P=0.000$ ) (Table 3).

When stratified with ethnicity, the outcomes revealed that this polymorphism was statistically related with increased risk of musculoskeletal degenerative diseases in Asian populations under all genetic models studied (allele model: $\mathrm{OR}=1.49,95 \%$ CI $1.25-1.77, \quad P=0.000$; homozygote model: $\mathrm{OR}=2.28,95 \% \mathrm{CI} 1.71-3.05, P=$ 0.000 ; heterozygote model: $\mathrm{OR}=1.49,95 \% \mathrm{CI} 1.25-1.78$, $P=0.000$; dominant model: $\mathrm{OR}=1.82,95 \% \mathrm{CI} 1.54-2.16$, $P=0.000$; recessive model: $\mathrm{OR}=1.55,95 \%$ CI $1.25-1.92$, $P=0.000$ ). In the Caucasian subgroup, a significant relationship between rs143383 polymorphism and increased 
Table 3 Meta-analysis of the association between GDF5 rs143383 and musculoskeletal degenerative diseases

\begin{tabular}{|c|c|c|c|c|c|c|c|}
\hline \multirow[t]{2}{*}{ GDF5 rs143383 } & \multirow[t]{2}{*}{ Subgroup } & \multicolumn{3}{|c|}{ Assessment of association } & \multicolumn{3}{|c|}{ Assessment of heterogeneity } \\
\hline & & $\mathrm{OR}$ & $95 \% \mathrm{Cl}$ & $P$ & Pooling model & $\mathrm{I}^{2}(\%)$ & $P$ \\
\hline \multirow[t]{7}{*}{ Allelic model } & Overall & 1.32 & $1.19-1.48$ & 0.000 & Random & 72.8 & 0.000 \\
\hline & Disease & & & & & & \\
\hline & IDD & 1.45 & $1.13-1.86$ & 0.004 & Random & 67.6 & 0.005 \\
\hline & $\mathrm{OA}$ & 1.28 & $1.14-1.44$ & 0.000 & Random & 73.4 & 0.000 \\
\hline & Ethnicity & & & & & & \\
\hline & Asian & 1.49 & $1.25-1.77$ & 0.000 & Random & 83.2 & 0.000 \\
\hline & Caucasian & 1.18 & $1.09-1.28$ & 0.000 & Fixed & 17.1 & 0.276 \\
\hline \multirow[t]{7}{*}{ Homozygote model } & Overall & 1.80 & $1.49-2.16$ & 0.000 & Fixed & 47.5 & 0.007 \\
\hline & Disease & & & & & & \\
\hline & IDD & 2.33 & $1.55-3.51$ & 0.000 & Fixed & 29.5 & 0.203 \\
\hline & $\mathrm{OA}$ & 1.67 & $1.36-2.05$ & 0.000 & Random & 50.1 & 0.014 \\
\hline & Ethnicity & & & & & & \\
\hline & Asian & 2.28 & $1.71-3.05$ & 0.000 & Random & 58.9 & 0.009 \\
\hline & Caucasian & 1.46 & $1.23-1.74$ & 0.000 & Fixed & 0.0 & 0.460 \\
\hline \multirow[t]{7}{*}{ Heterozygote model } & Overall & 1.37 & $1.21-1.55$ & 0.000 & Fixed & 26.7 & 0.122 \\
\hline & Disease & & & & & & \\
\hline & IDD & 1.84 & $1.34-2.52$ & 0.000 & Fixed & 0.0 & 0.926 \\
\hline & $\mathrm{OA}$ & 1.29 & $1.13-1.48$ & 0.000 & Fixed & 38.4 & 0.065 \\
\hline & Ethnicity & & & & & & \\
\hline & Asian & 1.49 & $1.25-1.78$ & 0.000 & Fixed & 15.5 & 0.300 \\
\hline & Caucasian & 1.27 & $1.07-1.51$ & 0.006 & Fixed & 33.8 & 0.120 \\
\hline \multirow[t]{7}{*}{ Dominant model } & Overall & 1.56 & $1.39-1.75$ & 0.000 & Fixed & 40.5 & 0.026 \\
\hline & Disease & & & & & & \\
\hline & IDD & 2.11 & $1.57-2.86$ & 0.000 & Fixed & 0.0 & 0.569 \\
\hline & $\mathrm{OA}$ & 1.46 & $1.29-1.66$ & 0.000 & Fixed & 46.2 & 0.026 \\
\hline & Ethnicity & & & & & & \\
\hline & Asian & 1.82 & $1.54-2.16$ & 0.000 & Fixed & 47.8 & 0.045 \\
\hline & Caucasian & 1.35 & $1.15-1.58$ & 0.000 & Fixed & 14.9 & 0.299 \\
\hline \multirow[t]{7}{*}{ Recessive model } & Overall & 1.39 & $1.20-1.60$ & 0.000 & Random & 73.3 & 0.000 \\
\hline & Disease & & & & & & \\
\hline & IDD & 1.44 & $1.02-2.04$ & 0.037 & Random & 71.4 & 0.002 \\
\hline & $\mathrm{OA}$ & 1.35 & $1.16-1.59$ & 0.000 & Random & 74.0 & 0.000 \\
\hline & Ethnicity & & & & & & \\
\hline & Asian & 1.55 & $1.25-1.92$ & 0.000 & Random & 83.2 & 0.000 \\
\hline & Caucasian & 1.21 & $1.03-1.42$ & 0.019 & Fixed & 36.2 & 0.101 \\
\hline
\end{tabular}

$I D D$ intervertebral disc degeneration, $O A$ osteoarthritis, $O R$ odds ratio, $C I$ confidence interval

risk of musculoskeletal degenerative diseases under all genetic models was also observed in our study (allele model: $\mathrm{OR}=1.18,95 \%$ CI 1.09-1.28, $\mathrm{P}=0.000$; homozygote model: $\mathrm{OR}=1.46,95 \% \mathrm{CI} 1.23-1.74, \mathrm{P}=0.000$; heterozygote model: $\mathrm{OR}=1.27,95 \% \mathrm{CI} 1.07-1.51, P=0.006$; dominant model: $\mathrm{OR}=1.3595 \% \mathrm{CI} 1.15-1.58, P=0.000$; recessive model: $\mathrm{OR}=1.21,95 \% \mathrm{CI} 1.03-1.42, P=0.019$ ) (Table 3).
Publication bias and sensitivity analysis

No obvious publication bias was shown in the funnel plot. In addition, there was no obvious publication bias according to Begg's test $(P=0.338)$ and Egger's test $(P=0.246)$. Therefore, we could exclude the possibility of publication bias. The sensitivity analysis revealed that the main outcomes of our study did not alter greatly when deleting studies one by one (Additional file 2). 


\section{Discussion}

Musculoskeletal degenerative diseases including IDD and $\mathrm{OA}$ are multifactorial diseases that bring about physical and functional limitations in patients. Various genetic risk factors may be responsible for the leading causes of IDD or OA [26, 27]. Previous studies have revealed that GDF5 polymorphism to be related with IDD, but with inconsistent results. Therefore, our study was made to assess the association between GDF5 rs143383 polymorphism and the susceptibility of IDD and OA. 15 articles with 915 patients and 12,252 controls were in our study. Eligible articles contained three studies in seven independent populations about IDD risk, and twelve studies assessed outcomes of GDF5 rs143383 on the risk of $\mathrm{OA}$ in fifteen independent populations.

GDF5 (+ 104 T/C; rs143383) is supposed to bring out a reduced transcription activity [28]. Our study revealed that GDF5 rs143383 polymorphism was significantly related with susceptibility to musculoskeletal degenerative diseases under all genetic models studied. Stratified analyses based on disease type showed a significant relationship between GDF5 rs143383 T allele and increased risk of IDD and OA. When stratified with ethnicity, the outcomes revealed that GDF5 rs143383 was statistically related with susceptibility to musculoskeletal degenerative diseases in both Asians and Caucasians.

Relatively obvious heterogeneities existed under all five genetic models in our study. With the aim of detecting the source of heterogeneity, we conducted sensitivity analysis and found that none articles altered the pooled OR significantly. Furthermore, we predicted that disease type and ethnicity may account for the heterogeneity and stratified analyses were then conducted. Neither the Egger test nor the Begg's funnel plot revealed obvious publication bias for the IDD or OA risk related with GDF5 polymorphism. Even though the outcomes are reliable, additional studies are warranted to further confirm the findings.

Taken all these data in consideration, our study has several strengths. First, we utilized a comprehensive search method with well-defined inclusion and exclusion criteria. Second, two investigators accessed the eligibility of articles and selected related data separately. Third, we assessed the quality of included studies by well-defined criteria and the scores here were high. Finally, stratified analyses based on disease type and ethnicity were conducted to get a generalized conclusion.

Whereas, several limitations still existed in our study. First, the sample sizes in our study are relatively limited, which might bring about the insufficiency of statistical power. Second, the majority of articles included merely assessed the relationship between the gene polymorphism with IDD or OA risk, and more precise OR adjusted for other covariates such as age, sex, and environmental factors were not accessible. Finally, we concluded merely one representative SNP and articles including other GDF5 polymorphisms are needed.

\section{Conclusion}

Our study demonstrated that GDF5 rs143383 polymorphism was significantly related with susceptibility to musculoskeletal degenerative. More studies are warranted to investigate the value of GDF5 polymorphisms and variations in other genes for years to come.

\section{Additional files}

Additional file 1: Table S1. Quality assessment of eligible studies (Newcastle-Ottawa Scale). Table S2. Definitions of disease or inclusions and exclusions in eligible studies. (DOCX 26 kb)

Additional file 2: Figure S2. Funnel plot for GDF5 polymorphism in musculoskeletal degenerative diseases. Figure S3. Begg's funnel plot for GDF5 polymorphism in musculoskeletal degenerative diseases. Figure S4. Egger's funnel plot for GDF5 polymorphism in musculoskeletal degenerative diseases. Figure S5. Sensitivity analysis for GDF5 polymorphism in musculoskeletal degenerative diseases. (DOCX 864 kb)

\section{Acknowledgements}

This study was supported by the National Key Research and Development Program of China (2016YFC1100100) and the Major Research Plan of National Natural Science Foundation of China (No. 91649204).

\section{Funding}

This study was funded by the National Key Research and Development Program of China (2016YFC1100100) and the Major Research Plan of National Natural Science Foundation of China (No. 91649204).

Availability of data and materials

All data generated or analyzed during this study are included in this published article and its supplementary information files.

\section{Authors' contributions}

XH: study design, data extraction and analysis, manuscript writing; ZWS: study design, and final approval of the manuscript; WYZ: data extraction, manuscript writing and critical appraisal. All authors read and approved the final manuscript.

Ethics approval and consent to participate

Not applicable.

Consent for publication

Not applicable.

\section{Competing interests}

The authors declare that they have no competing interests.

\section{Publisher's Note}

Springer Nature remains neutral with regard to jurisdictional claims in published maps and institutional affiliations.

\section{Author details}

${ }^{1}$ Department of Orthopaedics, Union Hospital, Tongji Medical College, Huazhong University of Science and Technology, Wuhan 430022, China. ${ }^{2}$ Department of Endocrinology, Union Hospital, Tongji Medical College, Huazhong University of Science and Technology, Wuhan 430022, China. 
Received: 18 June 2018 Accepted: 9 September 2018

\section{Published online: 14 September 2018}

\section{References}

1. Benoist M. The natural history of lumbar disc herniation and radiculopathy Joint Bone Spine. 2002;69:155-60.

2. Bailey AJ, Knott L. Molecular changes in bone collagen in osteoporosis and osteoarthritis in the elderly. Exp Gerontol. 1999;34:337-51.

3. Houard X, Goldring MB, Berenbaum F. Homeostatic mechanisms in articular cartilage and role of inflammation in osteoarthritis. Curr Rheumatol Rep. 2013;15.

4. Kalb S, Martirosyan NL, Kalani MYS, Broc GG, Theodore N. Genetics of the degenerated intervertebral disc. World Neurosurg. 2012;77:491-501.

5. Mishara A, Sanghi D, Chandra Sharma A, Raj S, Shanker Maurya S, Avasthi S. Association of Polymorphism in growth and differentiation factor 5 gene with osteoarthritis knee. Am J Biochem Biotechnol. 2013:9:1-7.

6. Zhang R, Yao JF, Xu P, Ji BH, Luck JV, Chin B, et al. A comprehensive metaanalysis of association between genetic variants of GDF5 and osteoarthritis of the knee, hip and hand. Inflamm Res. 2015;64:405-14.

7. Feng CC, Liu H, Yang Y, Huang B, Zhou Y. Growth and differentiation Factor-5 contributes to the structural and functional maintenance of the intervertebral disc. Cell Physiol Biochem. 2015;35:1-16.

8. Francis-West PH, Abdelfattah A, Chen P, Allen C, Parish J, Ladher R, et al. Mechanisms of GDF-5 action during skeletal development. Development. 1999:126:1305-15.

9. Nishitoh $\mathrm{H}$, Ichijo H, Kimura M, Matsumoto T, Makishima F, Yamaguchi A, et al. Identification of type I and type II serine/threonine kinase receptors for growth/differentiation factor-5. J Biol Chem. 1996;271:21345-52.

10. Mikic B, Battaglia TC, Taylor EA, Clark RT. The effect of growth/differentiation factor-5 deficiency on femoral composition and mechanical behavior in mice. Bone. 2002;30:733-7.

11. Li XD, Leo BM, Beck G, Balian G, Anderson DG. Collagen and proteoglycan abnormalities in the GDF-5-deficient mice and molecular changes when treating disk cells with recombinant growth factor. Spine. 2004;29:2229-34

12. Chujo T, An HS, Akeda K, Miyamoto K, Muehleman C, Attawia M, et al. Effects of growth differentiation factor-5 on the intervertebral disc - in vitro bovine study and in vivo rabbit disc degeneration model study. Spine. 2006; 31:2909-17.

13. Le Maitre CL, Freemont AJ, Hoyland JA. Expression of cartilage-derived morphogenetic protein in human intervertebral discs and its effect on matrix synthesis in degenerate human nucleus pulposus cells. Arthritis Res Ther. 2009:11.

14. Hao SW, Jin QH. Association between the $+104 \mathrm{~T} / \mathrm{C}$ polymorphism in the 5 ' UTR of GDF5 and susceptibility to knee osteoarthritis: a meta-analysis. Mol Med Rep. 2013:7:485-8.

15. Pan F, Tian J, Winzenberg T, Ding CH, Jones G. Association between GDF5 rs143383 polymorphism and knee osteoarthritis: an updated meta-analysis based on 23,995 subjects. BMC Musculoskelet Disord. 2014;15.

16. Jiang D, Hao ZT, Fan DS, Guo W, Xu PC, Yin C, et al. Association between GDF5+104T/C polymorphism and knee osteoarthritis in Caucasian and Asian populations: a meta-analysis based on case-control studies. J Orthop Surg Res. 2016;11

17. Mu J, Ge W, Zuo X, Chen Y, Huang C. A SNP in the 5'UTR of GDF5 is associated with susceptibility to symptomatic lumbar disc herniation in the Chinese Han population. Eur Spine J. 2014;23:498-503.

18. Mu J, Ge W, Zuo X, Chen Y, Huang C. Analysis of association between IL1 beta, CASP-9, and GDF5 variants and low-back pain in Chinese male soldier: clinical article. Journal of neurosurgery Spine. 2013;19:243-7.

19. Williams FMK, Popham M, Hart DJ, de Schepper E, Bierma-Zeinstra S, Hofman A, et al. GDF5 single-nucleotide polymorphism rs143383 is associated with lumbar disc degeneration in northern European women. Arthritis Rheum. 2011;63:708-12.

20. Tuluce $Y$, Yildirim $I H$, Ozkol H, Edi ZL, Delen V. Is GDF5 gene promoter polymorphism +104T/C associated with osteoarthritis in the eastern of Turkey population? Cell Mol Biol. 2017;63:64-6.

21. Abd Elazeem Ml, Abdelaleem EA, Mohamed RA. Genetic influence of growth and differentiation factor 5 gene polymorphism (+ 104T/C) on the development of knee osteoarthritis and its association with disease severity. Eur J Rheumatol. 2017;4:98-103.

22. Sabah-Ozcan S, Korkmaz M, Balbaloglu O, Percin F, Yilmaz N, Erdogan Y, et al. Polymorphisms in the growth differentiation factor 5 (GDF 5) gene in knee osteoarthritis. Jcpsp-J Coll Physici. 2017;27:602-5.
23. Xiao JL, Meng JH, Gan YH, Zhou CY, Ma XC. Association of GDF5, SMAD3 and RUNX2 polymorphisms with temporomandibular joint osteoarthritis in female Han Chinese. J Oral Rehabil. 2015;42:529-36.

24. Hernandez JL, Weir BS. A disequilibrium coefficient approach to hardyWeinberg testing. Biometrics. 1989;45:53-70.

25. Egger M, Smith GD, Schneider M, Minder C. Bias in meta-analysis detected by a simple, graphical test. Brit Med J. 1997;315:629-34.

26. Battie MC, Videman T. Lumbar disc degeneration: epidemiology and genetics. J Bone Joint Surg Am. 2006;88(Suppl 2):3-9.

27. Peffers MJ, Balaskas P, Smagul A. Osteoarthritis year in review 2017: genetics and epigenetics. Osteoarthr Cartil. 2018:26:304-11.

28. Miyamoto Y, Mabuchi A, Shi DQ, Kubo T, Takatori Y, Saito S, et al. A functional polymorphism in the 5 ' UTR of GDF5 is associated with susceptibility to osteoarthritis. Nat Genet. 2007;39:529-33.

29. Tawonsawatruk T, Changthong T, Pingsuthiwong S, Trachoo O, Sura T, Wajanavisit W. A genetic association study between growth differentiation factor 5 (GDF 5) polymorphism and knee osteoarthritis in Thai population. J Orthop Surg Res. 2011;6.

30. Cao Z, Lee HS, Song JH, Yoon JW, Park YK, Nam SW, et al. Growth differentiation factor 5 [GDF5] Core promoter polymorphism is not associated with susceptibility to osteoarthritis of the knee in the Korean population. Korean J Pathol. 2010;44:404-9.

31. Valdes AM, Spector TD, Doherty S, Wheeler M, Hart DJ, Doherty M. Association of the DWA and GDF5 polymorphisms with osteoarthritis in UK populations. Ann Rheum Dis. 2009;68:1916-20.

32. Tsezou A, Satra M, Oikonomou P, Bargiotas K, Malizos KN. The growth differentiation factor 5 (GDF5) core promoter polymorphism is not associated with knee osteoarthritis in the Greek population. J Orthop Res. 2008;26:136-40

33. Yoshinari M. A functional polymorphism in the $5^{\prime}$ UTR of GDF5 is associated with susceptibility to osteoarthritis. Nat Genet. 2007;4.

34. Southam L, Rodriguez-Lopez J, Wilkins JM, Pombo-Suarez M, Snelling S, Gomez-Reino JJ, et al. An SNP in the 5'-UTR of GDF5 is associated with osteoarthritis susceptibility in Europeans and with in vivo differences in allelic expression in articular cartilage. Hum Mol Genet. 2007;16:2226-32.

35. Shin MH, Lee SJ, Kee SJ, Song SK, Kweon SS, Park DJ, et al. Genetic association analysis of GDF5 and ADAM12 for knee osteoarthritis. Joint Bone Spine. 2012;79:488-91.
Ready to submit your research? Choose BMC and benefit from:
- fast, convenient online submission
- thorough peer review by experienced researchers in your field
- rapid publication on acceptance
- support for research data, including large and complex data types
- gold Open Access which fosters wider collaboration and increased citations
- maximum visibility for your research: over $100 \mathrm{M}$ website views per year
At BMC, research is always in progress.
Learn more biomedcentral.com/submissions 